\title{
Phase Separation and Crystallization in High Hard Block Content Polyurethane Thin Films
}

\author{
Long Jiang ${ }^{1}$, Jia Wu ${ }^{1}$, Chinemelum Nedolisa ${ }^{2}{ }^{\dagger}{ }^{\prime}$ Iberto Saiani ${ }^{2},{ }^{\dagger}$ Hazel E. Assender ${ }^{1}$ \\ ${ }^{1}$ Department of Materials, University of Oxford, Parks Road, Oxford OX1 3PH, UK \\ ${ }^{2}$ School of Materials, University of Manchester, Grosvenor Street, Manchester M1 7HS, UK \\ ${ }^{\dagger}$ Corresponding author
}

\begin{abstract}
Following studies of bulk behaviour, the morphological evolution in thin films of linear TPUs with a high content of hard segment (HS) (from 70 to $100 \mathrm{wt} \%$ ) on annealing is investigated. In contrast to melt-quenched bulk samples, a mixed phase was obtained for as-spin-cast films, and then, on annealing, a phase-separated mesophase domain, as previously observed by scattering and TEM in bulk samples, was observed by AFM to form directly from the mixed phase. In addition to this overall phase behavior, a crystallization behavior unique to thin films was observed: samples of thickness less than $120 \mathrm{~nm} \&$ annealed at sufficiently high temperature developed large lamellar crystal blocks. Similar crystal blocks have also been found in thin films of a TPU with a more flexible chain extender, although in this case, with the greater HS/SS compatibility of this material, the phase separation behavior was not observed at all.
\end{abstract}


For Table of Contents use only

\section{Phase Separation and Crystallization in High Hard Block Content Polyurethane Thin Films}

Long Jiang ${ }^{1}$, Jia Wu ${ }^{1}$, Chinemelum Nedolisa ${ }^{2}{ }^{\dagger}$ Alberto Saiani $^{2}$, ${ }^{\dagger}$ Hazel E. Assender ${ }^{1}$

${ }^{1}$ Department of Materials, University of Oxford, Parks Road, Oxford OX1 3PH, UK

${ }^{2}$ School of Materials, University of Manchester, Grosvenor Street, Manchester M1 7HS, UK

${ }^{\dagger}$ Corresponding author

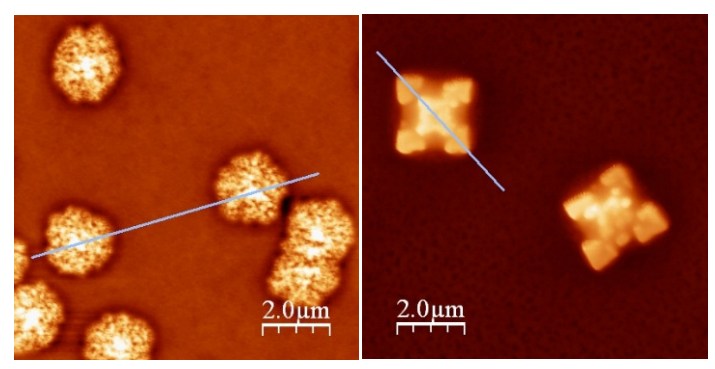




\section{INTRODUCTION}

Thermoplastic elastomers (TPEs) are versatile copolymers consisting of flexible soft segments (SS) and rigid hard segments (HS), which provide rubbery properties and act as physical crosslinks respectively. Among TPEs, thermoplastic polyurethanes (TPUs) are a representative group and have received much attention due to their wide application. It is believed that the intriguing properties of TPUs are due to their microphase-separated structures resulting from the thermodynamic immiscibility between the SS and HS. ${ }^{1}$ Thus, desirable properties of TPUs could be achieved by controlling types and lengths of the SS and $\mathrm{HS}^{2-5}$ the crystallinity of soft and hard phase domains, ${ }^{6,7}$ and the intersegment compatibility. ${ }^{8}$

Annealing can enhance mechanical and thermal properties of TPUs due to phase changes that can be characterised by the multiple endothermic peaks discovered in differential scanning calorimetry (DSC) traces, the subject of numerous previous investigations. ${ }^{9-19}$ Most of this work was carried out on polyurethanes with hard segments based on a 4,4'-methylenediphenylene isocyanate (MDI) extended by 1,4-butanediol, which is one of the most extensively investigated TPU classes. In general, three endotherms are reported in TPUs heated following an annealing treatment: a first endotherm, which is also known as the annealing endotherm $\left(T_{\mathrm{A}}\right)$ at roughly a few tens of Kelvin above the annealing temperature $\left(T_{\mathrm{a}}\right)$, and two high temperature endotherms (roughly within the range $\left.120-200{ }^{\circ} \mathrm{C}\right)$. Several phenomena have been proposed to explain the $T_{\mathrm{A}}$ including shortrange ordering of the $\mathrm{HS}^{9,10}$ (or of HS over a critical HS length, below which the HS is dissolved within the soft phase ${ }^{12,14}$ ), enthalpy relaxation (physical aging) of amorphous $\mathrm{HS}^{15}$ or interfacial materials,${ }^{16}$ and the formation of fringed micelle-like crystals in the HS domains. ${ }^{19}$ Early work attributed the intermediate endotherm to long-range ordering of the $\mathrm{HS}^{9,10}$ or the onset of the

formation of a homogeneous mixed phase,${ }^{14}$ and the last endotherm to melting of crystalline HS 
domains. Recent works, ${ }^{16-18}$ incorporating scattering data, explain the two high temperature endotherms as melting of HS crystals followed by HS/SS microphase mixing.

The origin of annealing-induced structural evolution in TPUs is of interest for its effect on properties, and because of the interplay between phase separation and ordering behaviours, however there is little work reported about the annealing effect on TPUs in thin-film situations or at the near-surface. Polymers in thin films are known to have distinct properties from those in bulk. The influence of the free- and substrate- surfaces can modify phase behaviour and crystallization morphologies through the effect of surface and interfacial energies, and of chain confinement. In addition, the increased mobility of chains near the free surface gives rise to a lower surface glass transition temperature $\left(T_{\mathrm{g}}\right)$, and polymer surface crystallization, for example, has been shown to occur at a temperature much lower than the bulk crystallization temperature $\left(T_{\mathrm{c}}\right)$ due to the lower $T_{\mathrm{g}}$ in the surface region. ${ }^{20} \mathrm{Hsu}$ and co-workers ${ }^{21,22}$ reported that the phase separation of TPUs in thin films would be restricted when the films thickness is below $200 \mathrm{~nm}$ and this effect becomes more obvious when the thickness is around $100 \mathrm{~nm}$. Later work by Kojio et al ${ }^{23}$ suggested that, below a certain film thickness, the crystallization of HS is confined, leading to a depression in phase-separated domain size. However, the morphology changes in TPU thin films are still largely uncharacterised. Here, we report for the first time the direct imaging of microphase-separated domains in high HS content TPU thin films using AFM.

In this study, the morphological evolution in thin films of linear TPUs with high HS content on annealing is examined to compare the phase behaviour with that in the bulk, to make direct observations of the phase morphologies, and to investigate any thin-film-specific phenomena such as vertical segregation and free-surface crystallization. Effects of annealing, HS content, film thickness and chain extender are extensively investigated. 


\section{EXPERIMENTAL}

A prepolymer (two-step) polymerization process was used for synthesis ${ }^{16-18}$ of TPUs that are poly(propylene oxide) end-capped, with ethylene oxide (EO-PPO-EO) as the SS and a short diol chain-extended MDI as the HS. The chain extenders (CE) in the HS is either 2-methyl-1,3-propanediol (2M13PD) or 1,5-pentanediol (15PD). Replacement of the chain extender 1,4-butanediol with these diols lowers the melting temperature, thus allowing annealing studies up to the melting point. ${ }^{17}$ TPUs are designated with the label of CE-XX where XX is the weight percentage of the HS, i.e. MDI plus CE. Molecular weights of the TPUs were obtained by gel permeation chromatography (GPC) and are listed in Table 1.

Table 1 Molecular weights and polydispersities for the polyurethanes used.

\begin{tabular}{ccccc}
\hline CE used & HS wt $\%$ & $\boldsymbol{M}_{\mathbf{w}}(\mathbf{g} / \mathbf{m o l})$ & $\boldsymbol{M}_{\mathbf{n}}(\mathbf{g} / \mathbf{m o l})$ & $\boldsymbol{M}_{\mathbf{w}} / \boldsymbol{M}_{\mathbf{n}}$ \\
\hline 2M13PD & 70 & 69730 & 19160 & 3.64 \\
& 80 & 59400 & 15550 & 3.82 \\
& 90 & 75770 & 23930 & 3.17 \\
\multirow{4}{*}{ 15PD } & 100 & 77870 & 29390 & 2.65 \\
& 70 & 109130 & 29936 & 3.65 \\
& 90 & 81515 & 30650 & 2.66 \\
& 100 & 106710 & 36090 & 2.96 \\
\hline
\end{tabular}

Polyurethane films were prepared by spin coating solutions of the polyurethanes in dimethylacetamide (DMAC) (Aldrich) onto glass substrates. Prior to coating, the glass substrates were sonicated in detergent (several drops of Decon in $600 \mathrm{ml}$ deionized water) and deionized water for $10 \mathrm{~min}$ each, and then in acetone and isopropanol for $5 \mathrm{~min}$ in turn. Solutions were normally stirred overnight for sufficient dissolution and were filtered with PTFE syringe filters (200 nm pore size) prior to deposition to remove any impurities or undissolved polymer particles, which might act as nuclei for crystallization and phase separation. A drop of this solution was then spin coated at room temperature at $2000 \mathrm{rpm}$ for $1 \mathrm{~min}$ with an acceleration rate of $200 \mathrm{rpm} / \mathrm{s}$. The 
as-spin-cast samples were then dried in vacuum for two days. Film thickness was controlled by solution concentration and was measured by a Dektak profilometer (Veeco), using $1 \mathrm{mg}$ stylus force and a scan rate of $150 \mu \mathrm{m} / \mathrm{s}$.

The surface morphology of the TPU films was investigated using tapping mode AFM (Park Scientific Instruments) with both topography and phase images recorded under ambient conditions (AFM images were processed using a Nanotec Electronica WSxM software ${ }^{24}$ ). As-spin-cast TPU films were annealed at temperatures ranging from $40{ }^{\circ} \mathrm{C}$ to $190{ }^{\circ} \mathrm{C}$ for various times. The as-spin-cast morphology of each of the samples was characterised before annealing to ensure a constant starting point since some morphology developments discovered are slight and may be easily mis-attributed to as-spin-cast morphology.

The surface chemistry of some samples was also analysed by X-ray photoelectron spectroscopy (XPS) performed in an ion pumped VG Microtech CLAM 4 multi-channel detecting (MCD) analyser system. 250 Watt unmonochromated $\mathrm{Al} \mathrm{X-ray} \mathrm{excitation} \mathrm{was} \mathrm{used} \mathrm{and} \mathrm{the} \mathrm{analyser} \mathrm{was}$ operated at constant pass energy of $100 \mathrm{eV}$ for wide scans and $20 \mathrm{eV}$ for detailed scans. The neutral carbon peak was set at binding energy of $284.8 \mathrm{eV}$ to correct for any sample charging.

Differential scanning calorimetry (DSC) of melt-quenched 2M13PD- and 15PD- extended TPUs was performed on a DSC Q100 (TA Instruments) with a scan rate of $20^{\circ} \mathrm{C} / \mathrm{min}$. These data (given in supplementary information Figure S1\&S2 and Table S1) characterise the thermal behaviour of TPUs in bulk and are taken as a reference for examination of thin film behaviour.

Transmission electron microscopy (TEM) analysis was carried out for morphology and crystallinity investigations using a JEOL $2010 \mathrm{LaB}_{6}$ microscope operated at $100 \mathrm{kV}$. To prepare the samples for TEM, a poly(acrylic acid) (PAA) detachment method was used. ${ }^{25} \mathrm{~A}$ small drop of 
PAA solution ( $35 \mathrm{wt} \%$ in water) was placed on a TPU film and dried. The solidified PAA can then be detached from the substrate taking with it the TPU film (upper layers). When the PAA is dissolved in deionized water, a floating TPU film can be obtained. After being picked up onto a TEM grid and dried, the sample is ready for TEM analysis.

\section{RESULTS AND DISCUSSION}

\section{M13PD-Extended TPU Thin Films}

Previous work ${ }^{16,17}$ investigated the crystallization and phase separation behaviour in bulk 2M13PD-extended TPUs with high HS content (from 70 to $100 \mathrm{wt} \%$ ), and identified the origin of the multiple endotherms. The studies indicated that, for melt-quenched 2M13PD-extended samples, a two-phase morphology, consisting of a "pure" HS phase and a HS/SS mixed phase (with a HS content of $65 \mathrm{wt} \%$ ), is obtained when HS content is above $65 \mathrm{wt} \%$, while a single mixed phase is produced when the HS content is below that. The HS/SS mixed phase can subsequently microphase separate on annealing, and at higher temperatures a microphase mixing transition $\left(T_{\mathrm{MMT}}\right)$ is observed. The situation for the initial condition in as-spin-coated thin films, however, is observed to be different. AFM results of the TPUs with HS content more than $65 \%$ show that, for as-spin-cast TPU films of thickness around $72 \mathrm{~nm}$ of any of the compositions, a "homogeneous" surface morphology is observed (Figure 1a), with a low surface roughness of around RMS height $0.3 \mathrm{~nm}$. XPS results in Figure $1 \mathrm{~b}$ indicate a mixture of HS and SS at the surface, with the HS content in the surface regions increasing with the HS wt $\%$ in the material, implied by the decreased intensity of ether carbon. 

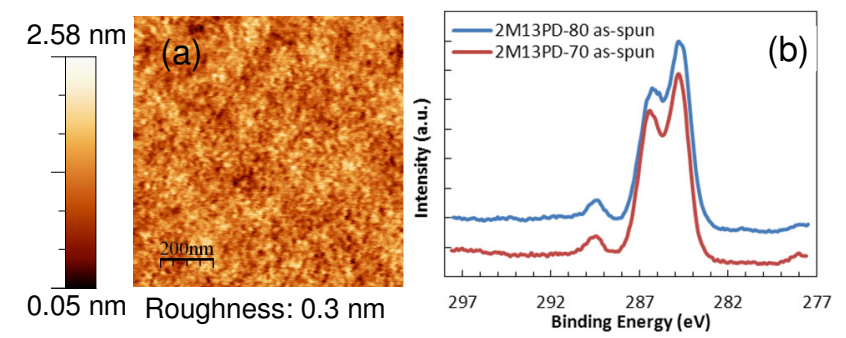

Figure 1 (a) Representative AFM topographic image showing as-spin-cast morphology of 2M13PD-90 TPU films with thickness around $72 \mathrm{~nm}$. As-spin-cast morphologies of other compositions (70, 80 and $100 \% \mathrm{HS}$ ) were very similar. (b) XPS C1s spectra for thin films of 2M13PD-70 and 2M13PD-80. The peaks observed at $284.8,286.4$ and $289.4 \mathrm{eV}$ are assigned to neutral $\left(\mathrm{CC}^{*} \mathrm{C}\right)$, ether $\left(\mathrm{C}^{*} \mathrm{O}\right)$ and urethane carbonyl $\left(\mathrm{NHC}^{*}(=\mathrm{O}) \mathrm{O}\right)$ carbon respectively. As HS content increases from 70 to $80 \mathrm{wt} \%$, the intensity for $\mathrm{NHC}^{*}(=\mathrm{O}) \mathrm{O}$ stays approximately constant, while the intensity for $\mathrm{C}^{*} \mathrm{O}$ decreases, indicating a decrease in SS content.

The melt-quenched samples were quenched at $20^{\circ} \mathrm{C} / \mathrm{min}$. Experiments carried out using liquid nitrogen to quench samples very rapidly from the melt resulted in fully mixed systems, as determined by scattering. Similarly, the high rate of quenching during the rapid solvent evaporation of these thin film samples, with a thickness of only $72 \mathrm{~nm}$, means that phase separation is severely restricted and therefore fails to develop before the polymer chains become immobile due to solvent evaporation. This agrees well with Hsu et al.'s work ${ }^{21,22}$ on polyurethanes in a restricted state.

\section{Morphological evolution on annealing}

Despite starting from a mixed phase rather than the two-phase morphology observed in the bulk, the same processes corresponding to the various DSC endotherms may still occur, albeit at slightly different temperatures from bulk samples due to the geometry confinement in very thin films. Here, 
2M13PD-90 is taken as an example to illustrate the evolution of the surface morphology in 2M13PD-extended TPU thin films on annealing. AFM images of as-spin-cast 2M13PD-90 films around $73 \mathrm{~nm}$ thick annealed at various temperatures from $90{ }^{\circ} \mathrm{C}$ to $160{ }^{\circ} \mathrm{C}$ for $16 \mathrm{hours}(\mathrm{hr})$ are shown in Figure 2.

In previous studies of bulk smples ${ }^{16}$ ordering of HS was observed on annealing. Due to the plasticizing effect of the SS, ordering of the HS in the mixed phase could even occur at annealing temperatures below the $T_{\mathrm{g}}$ of the hard phase $\left(T_{\mathrm{gHP}}\right)$, whereas the HS ordering in the "pure" HS phase requires an annealing temperature over $T_{\mathrm{gHP}}$. The HS ordering in both the mixed phase and the HS phase result in the crystal melting endotherm peak just below $T_{\text {MMт. }}$ Here, in 2M13PD-90 thin films annealed for $16 \mathrm{hr}$ there is an obvious change in surface morphology, first seen on annealing over $90{ }^{\circ} \mathrm{C}$ (Figure 2a), which is around $T_{\mathrm{gHP}}$ of bulk samples, $85^{\circ} \mathrm{C}$ (See supplementary information Table S2, $2^{\text {nd }}$ heating), in the form of raised areas (around $10 \mathrm{~nm}$ high). This morphology is observed to evolve as the annealing temperature increases. The first stages are initial HS ordering in aggregations of a mixture of crystalline HS and amorphous SS, since the mobility of pure HS would be very low at this temperature. When the annealing temperature is increased to $100{ }^{\circ} \mathrm{C}$ (Figure $2 \mathrm{~b}$ ) by which temperature the molecules are more mobile, the aggregations are observed of size $\sim 500 \mathrm{~nm}$ and height $\sim 40 \mathrm{~nm}$, and at $120^{\circ} \mathrm{C}$ (Figure 2c) and above they become micro-scale domains of HS/SS material at the surface, maintaining a similar height. 


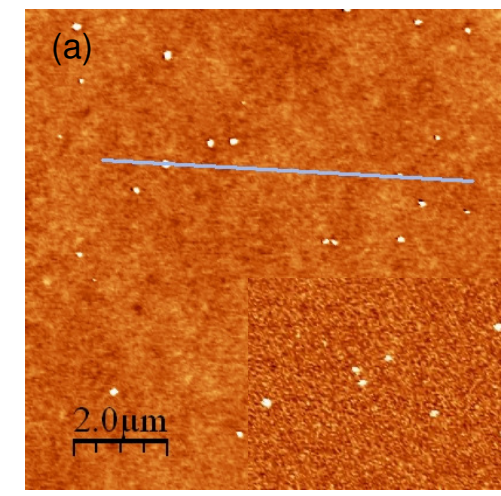

RMS roughness: $0.5 \mathrm{~nm}$
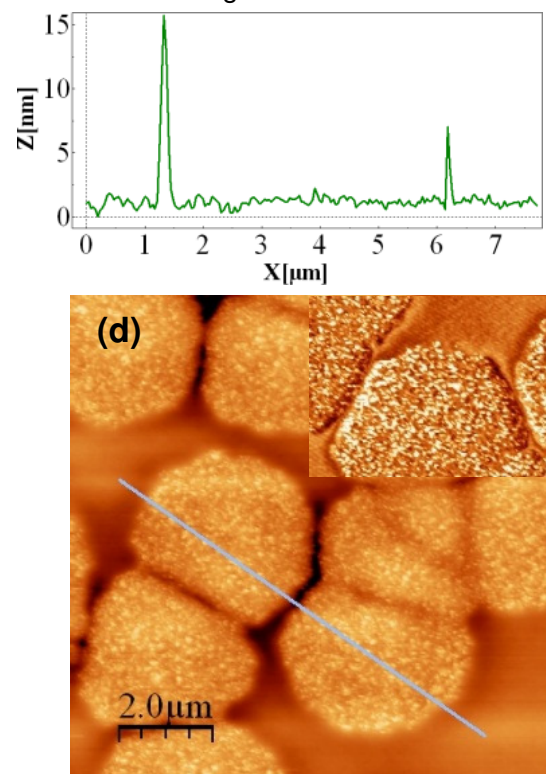

RMS roughness: $9.4 \mathrm{~nm}$

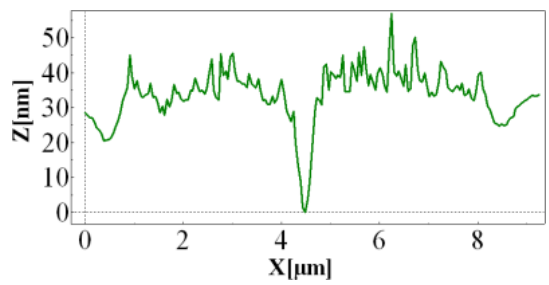

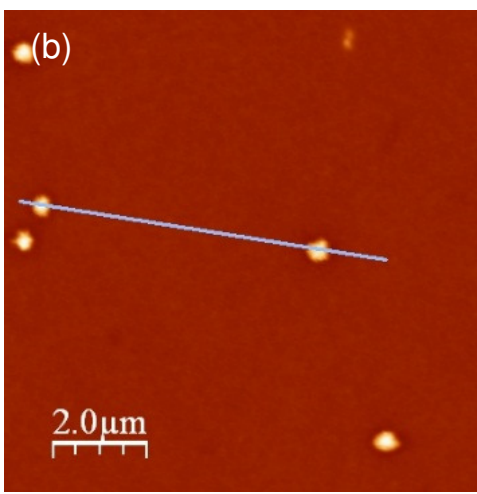

RMS roughness: $2.3 \mathrm{~nm}$
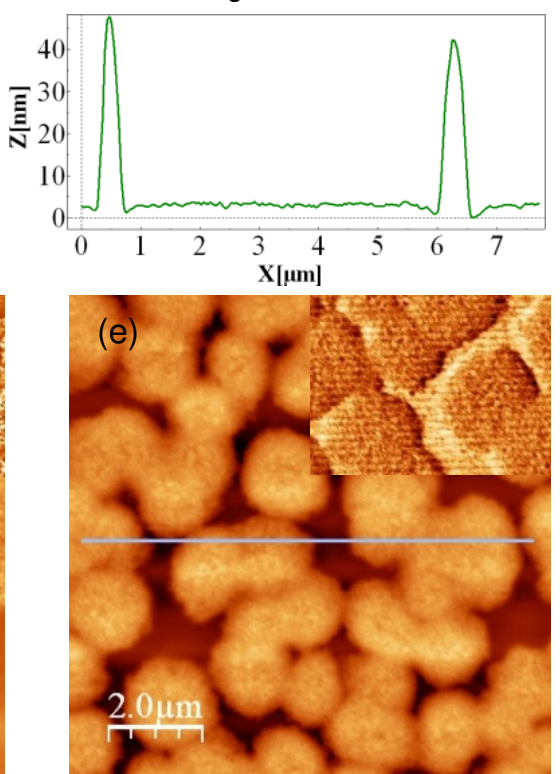

RMS roughness: $21.1 \mathrm{~nm}$

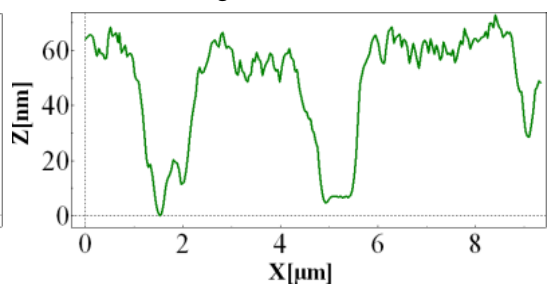

(c)

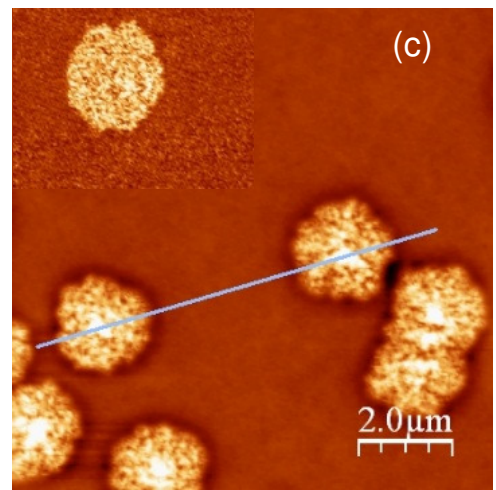

RMS roughness: $5.2 \mathrm{~nm}$
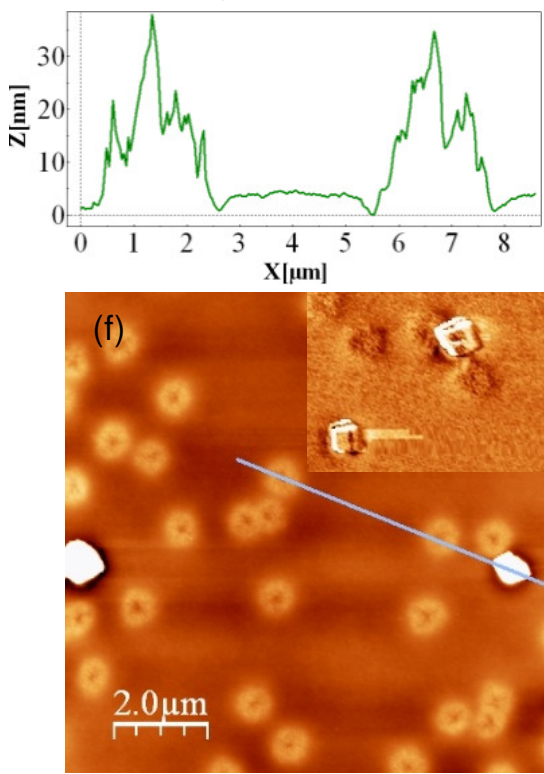

RMS roughness: $26.5 \mathrm{~nm}$

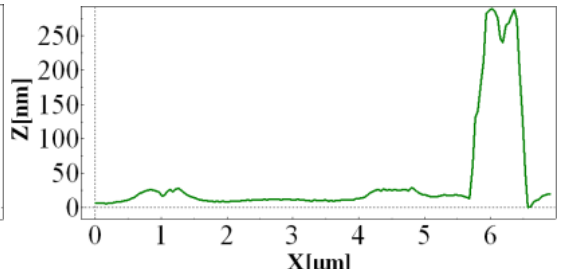

Figure 2 Phase separation and crystallisation on annealing. AFM height images of as-spin-cast 2M13PD-

90 films (73 $\pm 4 \mathrm{~nm}$ ) annealed at different temperatures for $16 \mathrm{hr}$ : (a) $90^{\circ} \mathrm{C}$, (b) $100{ }^{\circ} \mathrm{C}$, (c) $120^{\circ} \mathrm{C}$,

(d) $140{ }^{\circ} \mathrm{C}$, (e) $150{ }^{\circ} \mathrm{C}$, (f) $160{ }^{\circ} \mathrm{C}$, with height profiles beneath. The inserts in (a), (c-e) and (f) are the phase images of corresponding areas in the height images.

On annealing a melt-quenched bulk sample at $120^{\circ} \mathrm{C}$, the mixed phase domains undergo a microphase separation creating a phase-separated mesophase, ${ }^{18}$ and in the case of the thin films, 
the raised domains show a similar morphology to the so-called phase-separated mesophase observed in the bulk, with the height of the domain surface varying by about $25 \mathrm{~nm}$ (Figure 2c) across the plateau. The RMS height variation on a $1 \mu \mathrm{m} \times 1 \mu \mathrm{m}$ image on the top of the plateau is around $4.3 \mathrm{~nm}$, compared with the much smoother $0.4 \mathrm{~nm}$ between the domains. The domains exhibit bright speckles in the phase image (insert in Figure 2c) due to the higher modulus of the HS ordered regions within the mesophase. With this fine scale morphology, we recognise these phase-separated domains as the same phase-separated mesophase reported in bulk samples, but in this case it is developed directly from the as-spin-cast HS/SS mixed phase, leapfrogging the formation of the simple two-phase stage previously reported for the melt-quenched samples. Nevertheless, the HS content in the mesophase should tend to the composition in the meltquenched mixed phase domains, which is around $65 \mathrm{wt} \%,{ }^{16}$ whereas the HS content in the continuous phase increases with the growth of the microphase-separated mesophase and a "pure" HS phase would ultimately be obtained.

As the molecules have become sufficiently mobile, we might expect the film to have vertical phase-separated structure, as is often observed in multi-component thin films. XPS results of 2M13PD-80 films (Figure S3) indicate a decrease in the proportion of HS at the surface region during these phase separation processes, implied by the decreased intensity of urethane carbonyl carbon and the increased intensity of ether carbon, consistent with the formation of an upper layer with microphase-separated material of greater SS content.

The phase image indicates that, for annealing up to $140^{\circ} \mathrm{C}$, the regions between the mesophase domains are relatively soft (Figure $2 \mathrm{~d}$ ), even though, by this stage, these regions should be predominantly hard phase. The morphology in a sample annealed at $150{ }^{\circ} \mathrm{C}$ for $16 \mathrm{hr}$, however, suggests that there is HS ordering in the continuous phase, confirmed by the higher modulus than 
the mesophase indicated by the phase image (Figure 2e). This is consistent with observations of bulk 2M13PD-95 in which annealing at $120^{\circ} \mathrm{C}$ did not lead to ordering in the hard phase, but annealing at $160{ }^{\circ} \mathrm{C} \mathrm{did} .{ }^{16}$ The mesophase domains are smaller in the sample annealed at $150{ }^{\circ} \mathrm{C}$ than that at $140{ }^{\circ} \mathrm{C}$, but of greater number and height. This might be due to the hindered lateral mesophase growth rate by the now-crystalline surrounding hard phase.

AFM results of $2 \mathrm{M} 13 \mathrm{PD}-90$ films annealed at $160{ }^{\circ} \mathrm{C}$ (Figure $2 \mathrm{f}$ ), close to $T_{\mathrm{MMT}}$, reveal that a domain structure has only formed in a very limited fashion. Note that the as-spin cast material doesn't have domains, and during annealing above $T_{\mathrm{MMT}}$ they will never form. Thus, the thin film has a relatively smooth surface, however multilayer crystal blocks with height around $250 \mathrm{~nm}$ (these will be discussed in a later section) as well as small domains with height only around $20 \mathrm{~nm}$ are observed. An underlying or near-substrate layer may show a low density of domains, manifesting themselves as the 'soft edged' 20-nm high features, or these may possibly be proto-blocky crystals, suggested by the characteristic 'dip' in the centre of the feature that is also observed in the blocky crystals.

Annealing at temperatures higher still (e.g. $180^{\circ} \mathrm{C}$ ) revealed a morphology dominated by these large, blocky, crystals (Figure 3a). The as-spin-cast film was a single-phase mixture of HS and SS, and then in this case the annealing was carried out at a temperature above $T_{\text {MMT }}$ and the melting point $\left(T_{\mathrm{M}}\right)$ of ordered HS, so during annealing we expect no phase separation or micro-HS ordering, consistent with the AFM observations (Figure 3a). A selected area electron diffraction pattern of this region (Figure S4) shows diffuse diffraction rings, suggesting this region is largely amorphous. However, there may be small scale demixing/ordering possible during the sample cooling, and there is evidence of this in TEM imaging (Figure 3b) of the continuous region between the large crystals. Dark areas with diameters below $10 \mathrm{~nm}$ that might be associated with SS are observed, 
and the structure resembles the morphology of the microphase-separated mesophase in bulk samples observed by $\mathrm{TEM}^{18}$, but with a much lower proportion of soft phase. This result indicates that after annealing at $180{ }^{\circ} \mathrm{C}$ for $16 \mathrm{hr}$ the regions between the large crystals are in a mixed state with HS around $90 \mathrm{wt} \%$ rather than having a mesophase with HS around $65 \mathrm{wt}$ as would be expected for annealing below $T_{\text {MMT. }}$. The tiny white dots in Figure $3 \mathrm{~b}$ are assigned to the ordered HS structures in the matrix, presumably also formed during cooling.

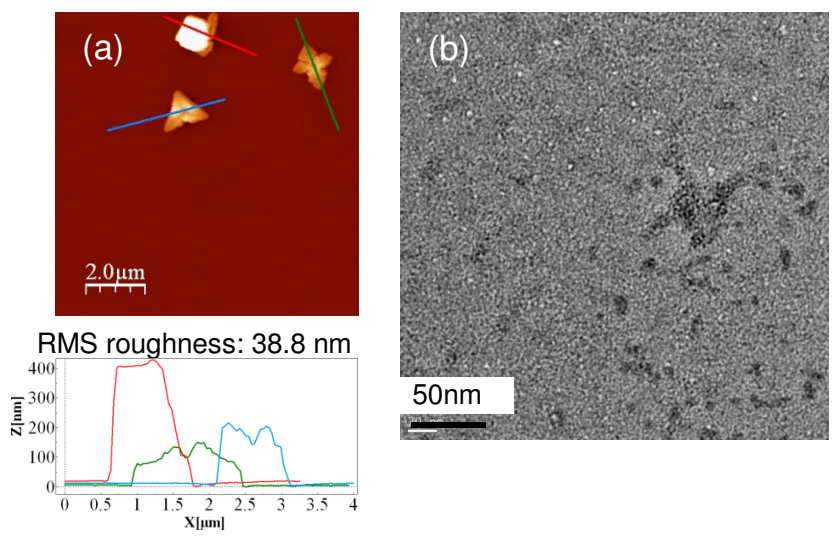

Figure 3 Morphology of 2M13PD-90 films $(73 \pm 4 \mathrm{~nm})$ annealed at $180^{\circ} \mathrm{C}$ for $16 \mathrm{hr}$ : (a) AFM height image with depth profile underneath, indicating the large blocky crystals, and the smooth surface between. TEM shows (b) small ordered HS domains and SS domains in the continuous mixed phase, thought to form on sample cooling.

\section{Influence of HS content}

The microphase separation and crystallization in TPUs depend greatly on the proportion of HS and SS: the lower the SS content, the lower the HS mobility. DSC (Figure S1) indicated that without any SS, crystallization of HS becomes difficult and no melting endotherms were detected. This agrees with our AFM results that, for $16 \mathrm{hr}$ annealing, only when the temperature is greater than $140{ }^{\circ} \mathrm{C}$ can a slight morphology change be detected in the form of very small peaks of height $15 \mathrm{~nm}$ (Figure S5) in 2M13PD-100 films. The morphology developments of 2M13PD-70, -80 
and -90 thin films (with thickness around $72 \mathrm{~nm}$ ) on annealing (16 hr) are displayed in Figure 4. In general, the TPU thin films develop from the as-cast amorphous microstructure through four main stages: initial formation of HS ordered regions, generation of microphase-separated mesophase domains at the surface, a relatively smooth upper layer of mixed phase (with only low features) and formation of large crystals or bulky aggregations.
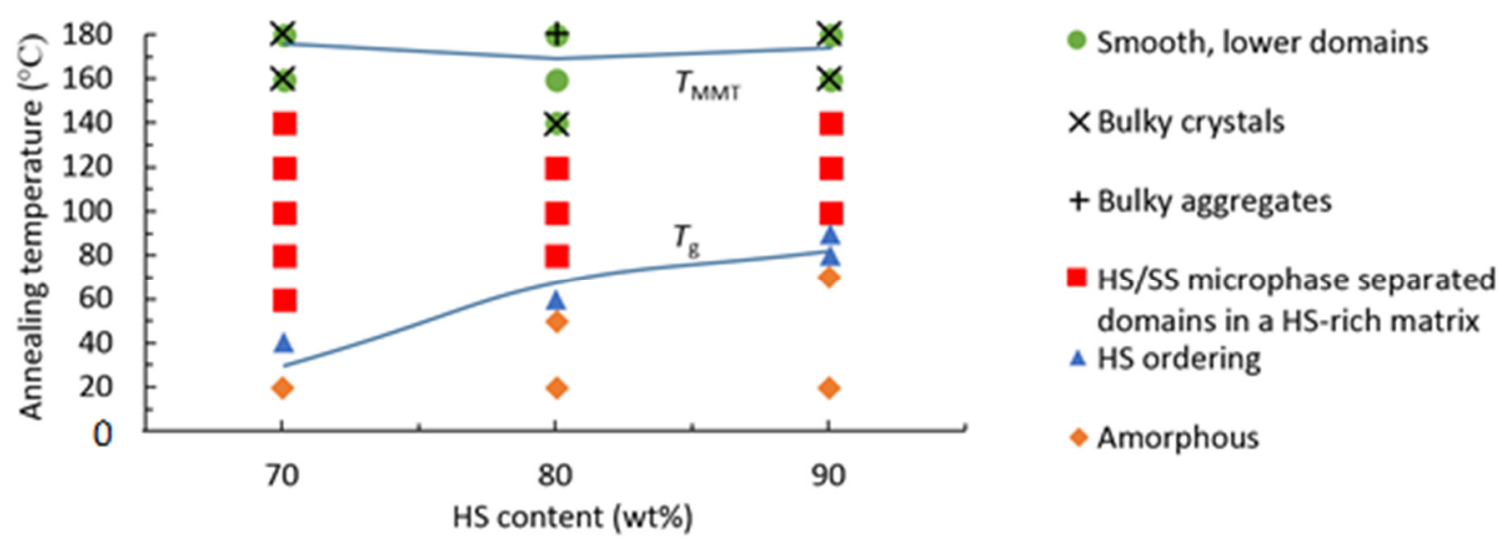

Figure 4 Morphological evolution of 2M13PD-extended high HS content TPU thin films (around $72 \mathrm{~nm}$ thick) on annealing. All samples were annealed for $16 \mathrm{hr}$.

The first stage is believed to be induced by the ordering of HS in the mixed phase (as-cast) in the form of small aggregations of several nanometres height and then larger domains of microphase-separated regions evolve at the surface. The lowest temperature where this occurs is approximately consistent, at all compositions, with the $T_{\mathrm{g}}$ of corresponding bulk samples (Figure S1b, Table S1) and correspondingly increases with the HS content. At temperatures around $T_{\text {MMT }}$ of the bulk, the domain structure is only weakly observed and the surface of the sample is relatively smooth (apart from any large crystals), commensurate with HS and SS remaining largely mixed (from this starting mixed condition before annealing), although there may well be some surface segregation of the soft segment. 
If there is a similar HS/SS ratio of the upper mesophase, (e.g. close to $65 \mathrm{wt} \% \mathrm{HS}$ ), regardless of the HS content of the TPU material, large HS crystals are expected to occur at temperatures independent of the composition of the TPU. This is confirmed by what we found in 2M13PD-70 and 2M13PD-90 films (Figure 4): both show bulky crystals at temperatures above $160{ }^{\circ} \mathrm{C}$. The annealing temperature required for bulky crystals in 2M13PD-80 films, however, is about $20 \mathrm{~K}$ lower. This is likely a result of the much lower molecular weight of 2M13PD-80 compared to 2M13PD-70 and 2M13PD-90, as indicated in Table 1. DSC (Figure S1a\&b and Table S1) also confirmed that $T_{\mathrm{MMT}}$ of $2 \mathrm{M} 13 \mathrm{PD}-80$ is lower than that of the other two polyurethanes.

\section{Thickness effects}

Increasing the film thickness accelerated and enlarged the various morphological developments. For example, annealing at $90{ }^{\circ} \mathrm{C}$ for $16 \mathrm{hr}$ only allows a $73 \mathrm{~nm}$ thick 2M13PD-90 film to form some small aggregations with height around $10 \mathrm{~nm}$ (Figure 2a), but enables aggregations with height around $25 \mathrm{~nm}$ (Figure S6a) and $30 \mathrm{~nm}$ (Figure S6c) for $127 \mathrm{~nm}$ and $363 \mathrm{~nm}$ thick films respectively. In samples annealed at $120^{\circ} \mathrm{C}$ for $16 \mathrm{hr}$, separated mesophase domains are observed in $73 \mathrm{~nm}$ films (Figure 2c), but they are beginning to impinge in $127 \mathrm{~nm}$ films (Figure S6b), and almost completely cover the surface in $363 \mathrm{~nm}$ films (Figure S6d). This implies a confined mobility of polymer chains in 2M13PD-extended TPU thin films below a few hundred nanometres, which agrees with the suggestion of Hsu et al... ${ }^{21,22}$

\section{PD-Extended TPU Thin Films}

By varying chain extenders, properties of the HS can be qualitatively modified. In contrast to the case in 2M13PD-extended TPU films (with thickness below $100 \mathrm{~nm}$ ), where microphase separation and HS ordering occur at low annealing temperatures and bulky multilayer crystals are 
generated at temperatures close to the $T_{\mathrm{MMT}}$ of bulk samples, annealed 15PD-extended TPU films of similar thickness show mainly crystallization processes, with no microphase-separated domains detected. Crystallization is more facile in 15PD-extended HS compared with the non-linear 2M13PD extender with steric hindrance from the side methyl.

With film thickness around 70 to $80 \mathrm{~nm}, 15 \mathrm{PD}$-extended TPU thin films show a rather smooth as-spin-cast morphology, with MS roughness below $0.3 \mathrm{~nm}$. A mixed phase was observed for these spin-cast thin films, as was found even with the more HS/SS-incompatible 2M13PD-extended TPU films. As for the 2M13PD-extended TPU films, 15PD-70, -90 and -100 thin films were annealed for $16 \mathrm{hr}$ at various temperatures. Even on annealing, there is no phase separation observed in the thin films. This is due to the significantly higher chain flexibility of 15PD compared to 2M13PD: extended by 15PD, the HS has an enhanced compatibility with SS, and therefore the tendency to phase separation between HS and SS is reduced. With HS/SS phase separation not favoured, high HS content 15PD-extended TPU films, e.g. 15PD-70, 15PD-90, show a similar morphological evolution to that of pure HS films, 15PD-100, on annealing, Figure 5. This lack of phase separation appears to be a thin film phenomenon, as multiple endotherms are observed in the DSC (Figure S2), suggesting both a $T_{\mathrm{M}}$ and a $T_{\mathrm{MMT}}$, the latter being associated with the phase-separated state. 


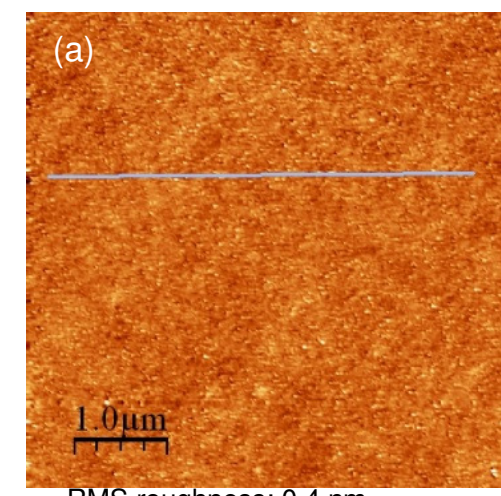

RMS roughness: $0.4 \mathrm{~nm}$
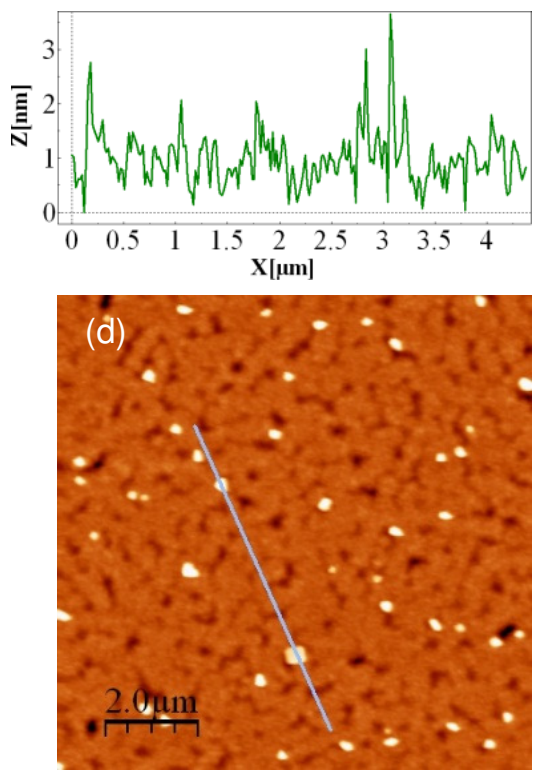

RMS roughness: $7.1 \mathrm{~nm}$

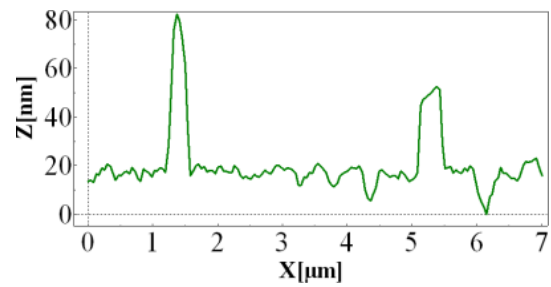

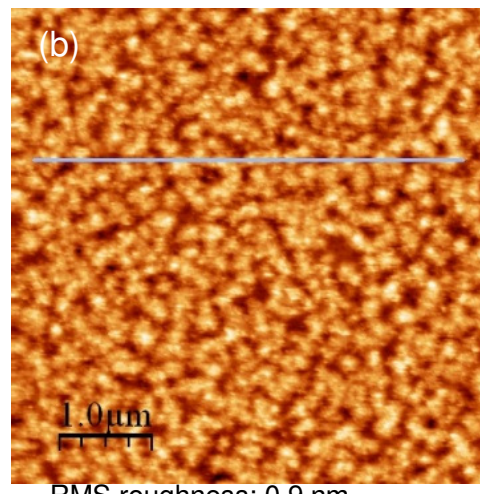

RMS roughness: $0.9 \mathrm{~nm}$
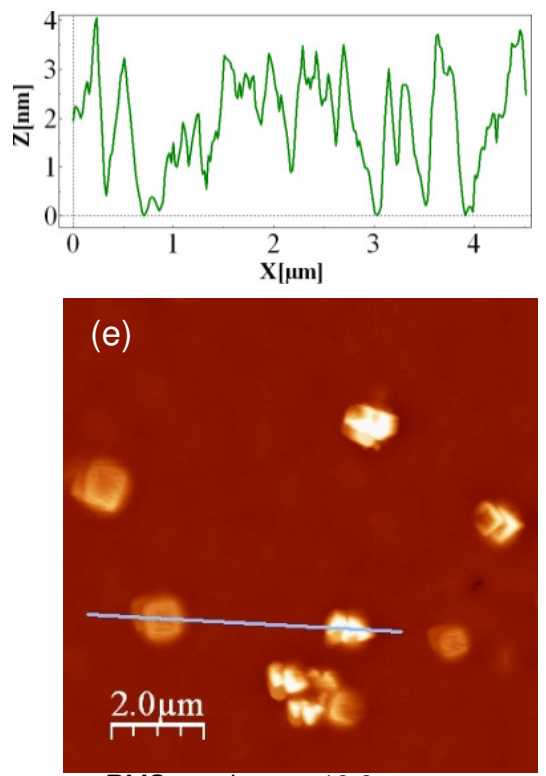

RMS roughness: $19.8 \mathrm{~nm}$

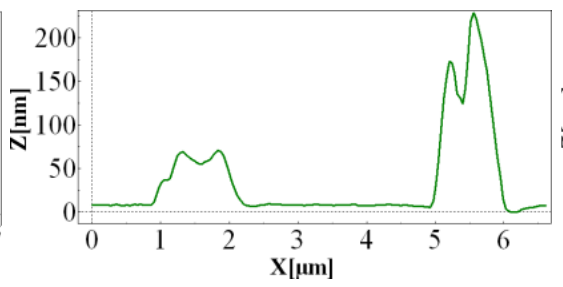

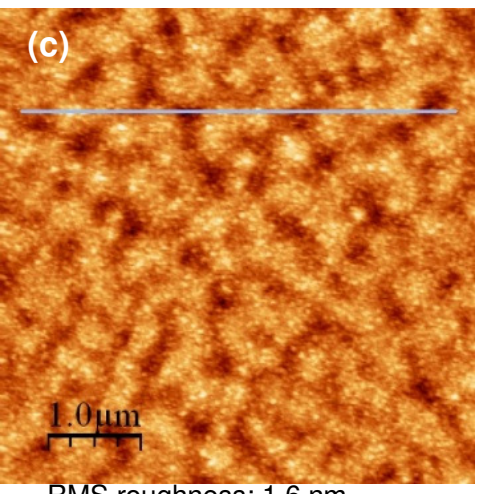

RMS roughness: $1.6 \mathrm{~nm}$
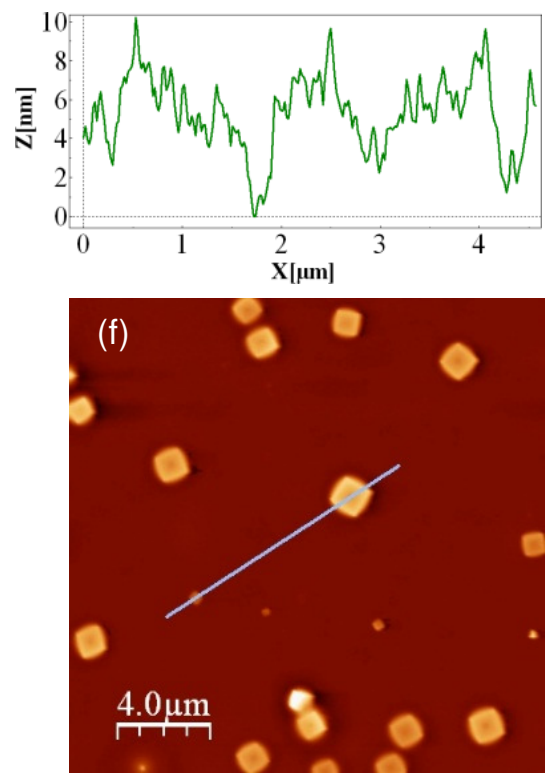

RMS roughness: $19.4 \mathrm{~nm}$

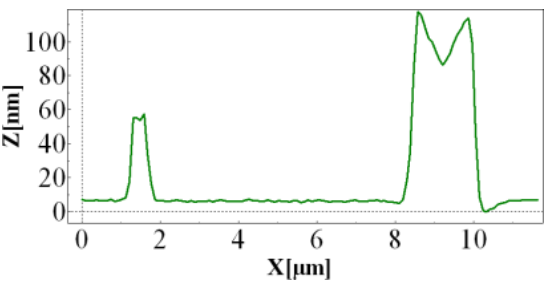

Figure 5 AFM height images of as-spin-cast 15PD-100 films $(69 \pm 5 \mathrm{~nm})$ after $16 \mathrm{hr}$ annealing at (a) $80{ }^{\circ} \mathrm{C}$, (b) $100{ }^{\circ} \mathrm{C}$, (c) $130{ }^{\circ} \mathrm{C}$, (d) $150{ }^{\circ} \mathrm{C}$, (e) $170{ }^{\circ} \mathrm{C}$ and (f) $190{ }^{\circ} \mathrm{C}$, with corresponding height profiles beneath. Note the scale changes between images.

The early stage of the development of surface morphology in 15PD-100 thin films (around $70 \mathrm{~nm}$ thick) is assigned to the HS ordering. This starts with the appearance of tiny aggregations with height of around a few nanometres (Figure 5a) when annealed at $80{ }^{\circ} \mathrm{C}$ which is around the $T_{\mathrm{g}}$ of 
melt-quenched 15PD-100 (Table S1). As annealing temperature increased, a significant growth was observed in these aggregations, and by $100{ }^{\circ} \mathrm{C}$ they densely cover the film surface (Figure $5 \mathrm{~b}$ ). The development of surface morphology here qualitatively resembles the morphology evolution in 2M13PD-70 films where the generation and joining of aggregations occur, which is recognised as the result of HS/SS phase separation and HS ordering. However, the aggregations and gaps in 2M13PD-70 films have height variations of tens of nanometres, while in 15PD-100 films, the features, which we associate only with HS ordering, are only a few nanometres in height, consistent with them being associated with localised ordering rather than larger-scale phase segregation. For 15PD-100 films, large, blocky crystals are first observed at $150{ }^{\circ} \mathrm{C}$ (Figure $5 \mathrm{~d}$ ). $T_{\mathrm{M}}$, as measured in bulk samples for $15 \mathrm{PD}-100$, is $167^{\circ} \mathrm{C}$ (Table S1), and on annealing the thin films above $170^{\circ} \mathrm{C}$ (Figure 5e and 5f), the small crystallites are not observed, leaving a smooth topography, but the large crystals (of higher melting point) remain, rising from the free surface.

The morphology developments of 15PD-extended high HS content TPU thin films on annealing are summarised in Figure 6. Basically, there are two phase changes on annealing. One is formation of ordered HS structure which appears in the form of small peaks or aggregations at relatively low annealing temperatures and lead to crystallization of the whole film with undulations or gaps formed at the surface at higher annealing temperatures. This transition takes place when annealed at a temperature over $T_{\mathrm{g}}$, which increases with HS content, and disappears around $T_{\mathrm{M}}$ of the ordered HS structures. The other distinctive morphological change is the development of large crystal blocks. The lowest temperatures needed for the generation of these crystal blocks is around the $T_{\mathrm{c}}$ of the melt-quenched bulk 15PD-extended polyurethanes (Table S1). 


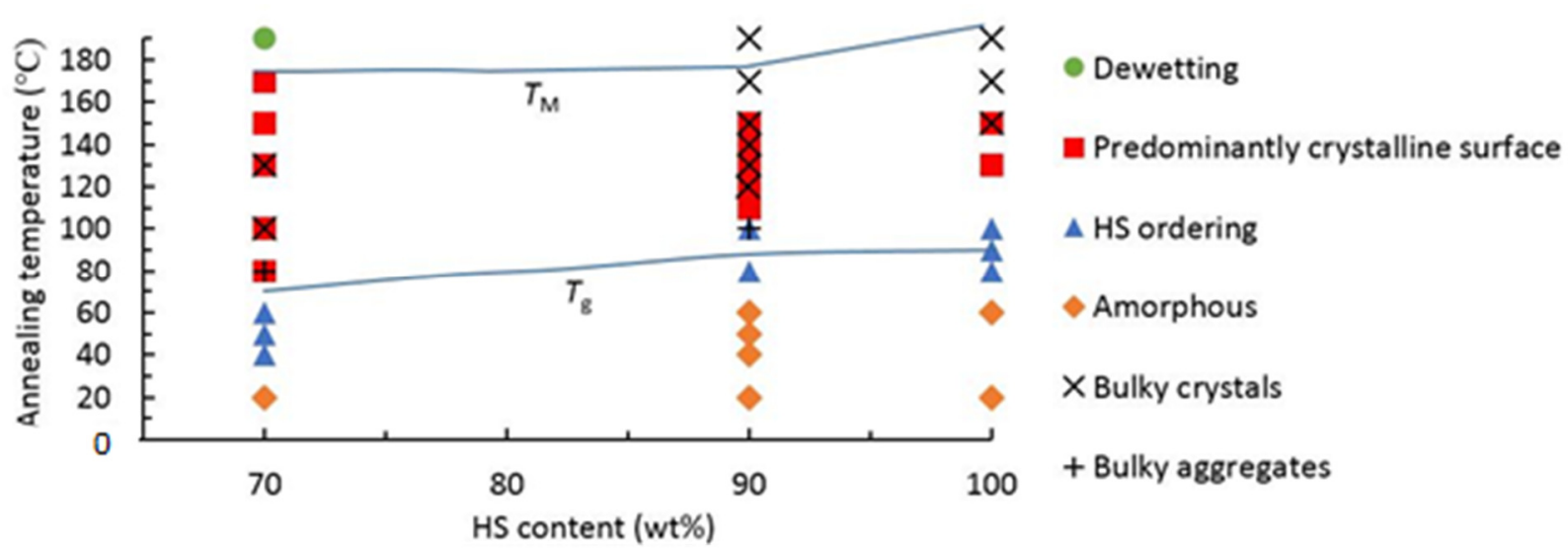

Figure 6 Morphological evolution of 15PD-extended high HS content TPU thin films (70-80 nm) on annealing (16 hr). Room temperature is assumed to be $20^{\circ} \mathrm{C}$.

In comparison with the 2M13PD sample, therefore, the tendency for phase separation between the HS and SS is reduced, but the mobility of the 15PD-extended system is greater (confirmed by the lower $T_{g}$ ), and thus crystal blocks occur at a lower temperature.

\section{Crystal Development}

An extraordinary aggregation-crystallization process observed in both suites of TPU materials allows the polymer chains to arrange themselves into big lamellar crystal blocks reaching hundreds of nanometres proud of the surface. It is clear from images of both classes of material (e.g. phase image of Figure 2f, and Figure 5e) that these crystals are stacks of square-shaped layers. These regular-shaped crystals show a similarity to the multilayer single crystals of polymers, e.g. polyethylene (PE), crystallized from dilute solution, with each lamellar layer typically $10 \mathrm{~nm}$ thick. ${ }^{26}$ For the TPUs with the stiffer chain extender, 2M13PD, no such crystals were found in the pure HS material on annealing, suggesting that these crystals require SS to form in this case, however the greater chain flexibility of the 15PD-extended HS allows significant formation of large crystals in all compositions, including $100 \%$ HS thin films. Since no such crystal blocks have 
been observed in bulk samples, we conclude that this is a specific thin-film phenomenon induced by either free surfaces or spatial confinement (film thickness).

Typical examples of the large crystals are shown in Figure 3a, with both a square block and seaweed morphology observed. In this case the crystals are observed in 2M13PD-90 thin films (73 $\pm 4 \mathrm{~nm}$ ) annealed at $180{ }^{\circ} \mathrm{C}$, a temperature greater than the $T_{\mathrm{M}}$ and the $T_{\mathrm{MMT}}$ of bulk samples (Figure S1 and Table S1). They are still stable at these temperatures presumably because these crystals are so much larger than the ordered structures reported in bulk samples. The multilayer crystal block can now be as high as $400 \mathrm{~nm}$, whereas the seaweed crystals rise to approximately 100 to $200 \mathrm{~nm}$. Extensive AFM work indicated that the crystals in this sample mainly appear with seaweed morphology with only a small proportion of square shaped crystals. The seaweed ones mostly have a cross pattern, while a few are in a triangular form. Figure 7 presents TEM micrographs of the large crystals with a corresponding selected area electron diffraction pattern. When the diffraction area was limited to the seaweed crystals (Figure 7b), multiple diffraction spots were observed, indicating several crystal orientations within the selected area.
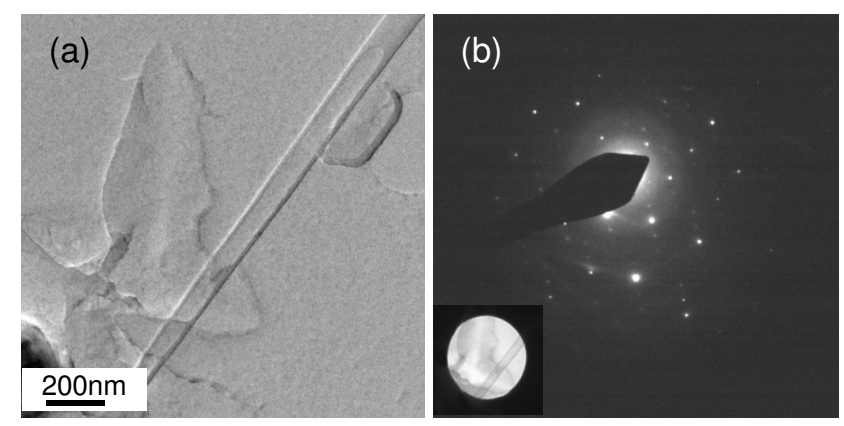

Figure 7 Crystal morphology of 2M13PD-90 films $(73 \pm 4)$ annealed at $180^{\circ} \mathrm{C}$ for $16 \mathrm{hr}$ : (a) large seaweed-morphology crystal and (b) selected-area diffraction pattern from (b) with the exact areas indicated in inserts. 
The composition of the TPU has little effect on the onset temperature for the formation of large crystals in 2M13PD-extended material, as the phase separation of the system gives rise to a constant composition in the upper mesophase. By contrast, there is a compositional variation in the onset of large crystal formation in the 15PD-extended system, with a greater proportion of SS leading to a lower onset temperature due to enhanced chain mobility.

There are differences in the morphologies observed between the materials with the different chain extenders, which is likely influenced by the non-linear chain extender in the case of 2M13PD which will give some steric hindrance to chain packing, compared with the linear case in 15PD, which should not perturb linear packing of the HS units. In addition, the proportion of HS influences the morphology of the crystals. The morphology of the 2M13PD-70 crystals is displayed in Figure 8. Compared to the crystals in 2M13PD-90 films, these crystals, obtained both at $160{ }^{\circ} \mathrm{C}$ and $180{ }^{\circ} \mathrm{C}$, are larger and less regular. When annealed at $180{ }^{\circ} \mathrm{C}$, rather than forming seaweed crystals, only crystals with subtly distinguished leaves were found in 2M13PD-70 films (Figure 8b\&b'). 

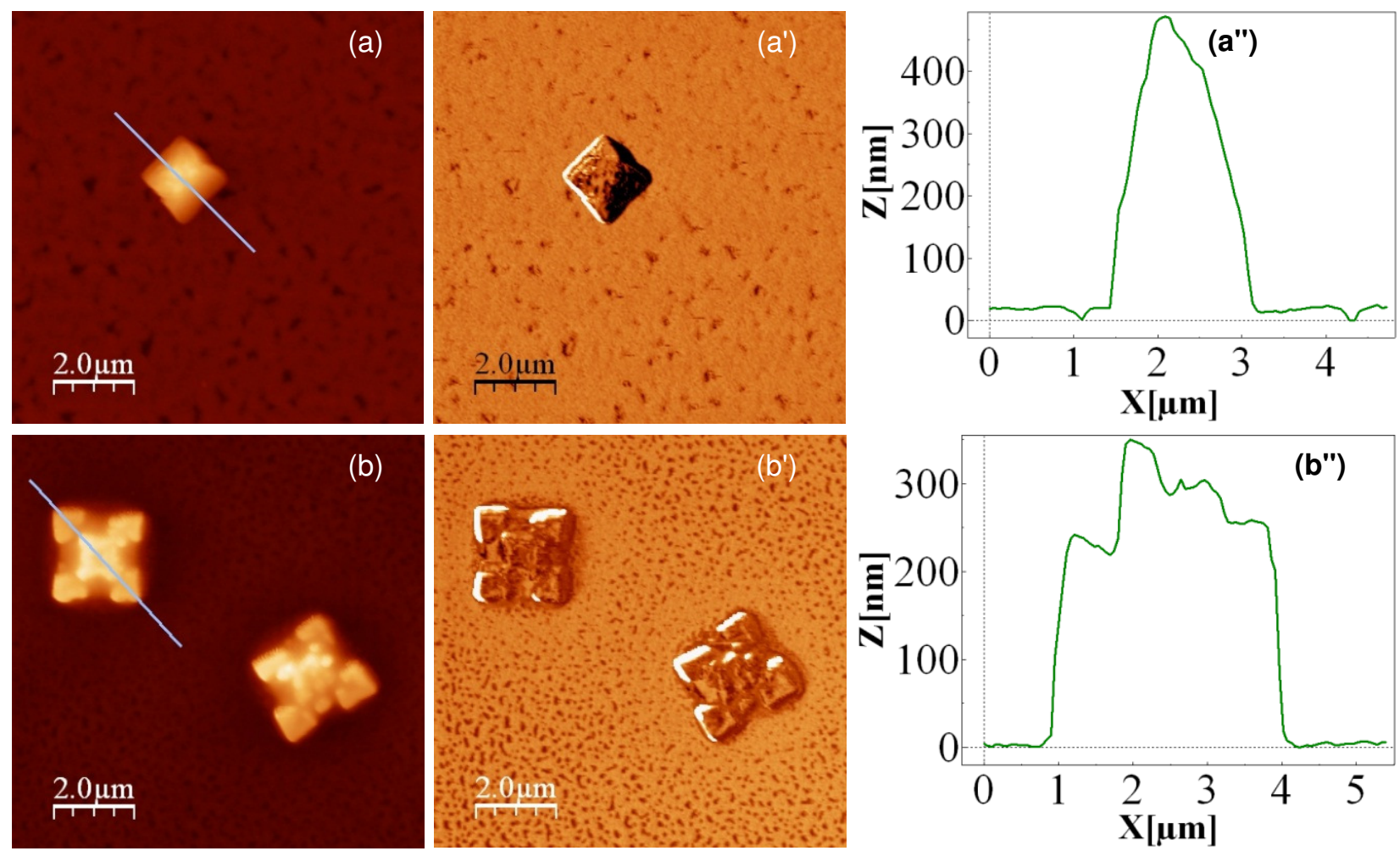

Figure 8 Crystals in $2 \mathrm{M} 13 \mathrm{PD}-70$ films $\left(72 \pm 6 \mathrm{~nm}\right.$ ) generated at (a) $160^{\circ} \mathrm{C}$ and (b) $180^{\circ} \mathrm{C}(16 \mathrm{hr})$ with corresponding phase images and height profile.

No large crystal blocks were found in thicker films with reduced thin film confinement. Further to our previous conclusion that these crystal blocks are specifically a thin-film phenomenon, their generation appears to rely on a film thickness less than about $100 \mathrm{~nm}$ in the case of 2M13PD-extended TPUs. For ultra-thin films, the confinement of chains in the film (and possible substrate interactions) reduces their mobility, meaning that a greater annealing temperature is required to induce aggregations and crystal formation. For instance, in 15PD-70 thin films around $79 \mathrm{~nm}$ thick, aggregations form after a $16 \mathrm{hr}$ anneal at $80^{\circ} \mathrm{C}$, whereas for $36 \mathrm{~nm}$ thick films, such aggregations do not form until the film is annealed for $16 \mathrm{hr}$ at $140{ }^{\circ} \mathrm{C}$ (Figure S7). 


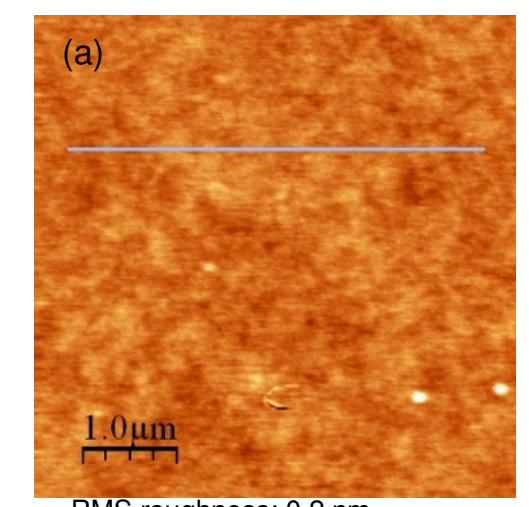

RMS roughness: $0.2 \mathrm{~nm}$
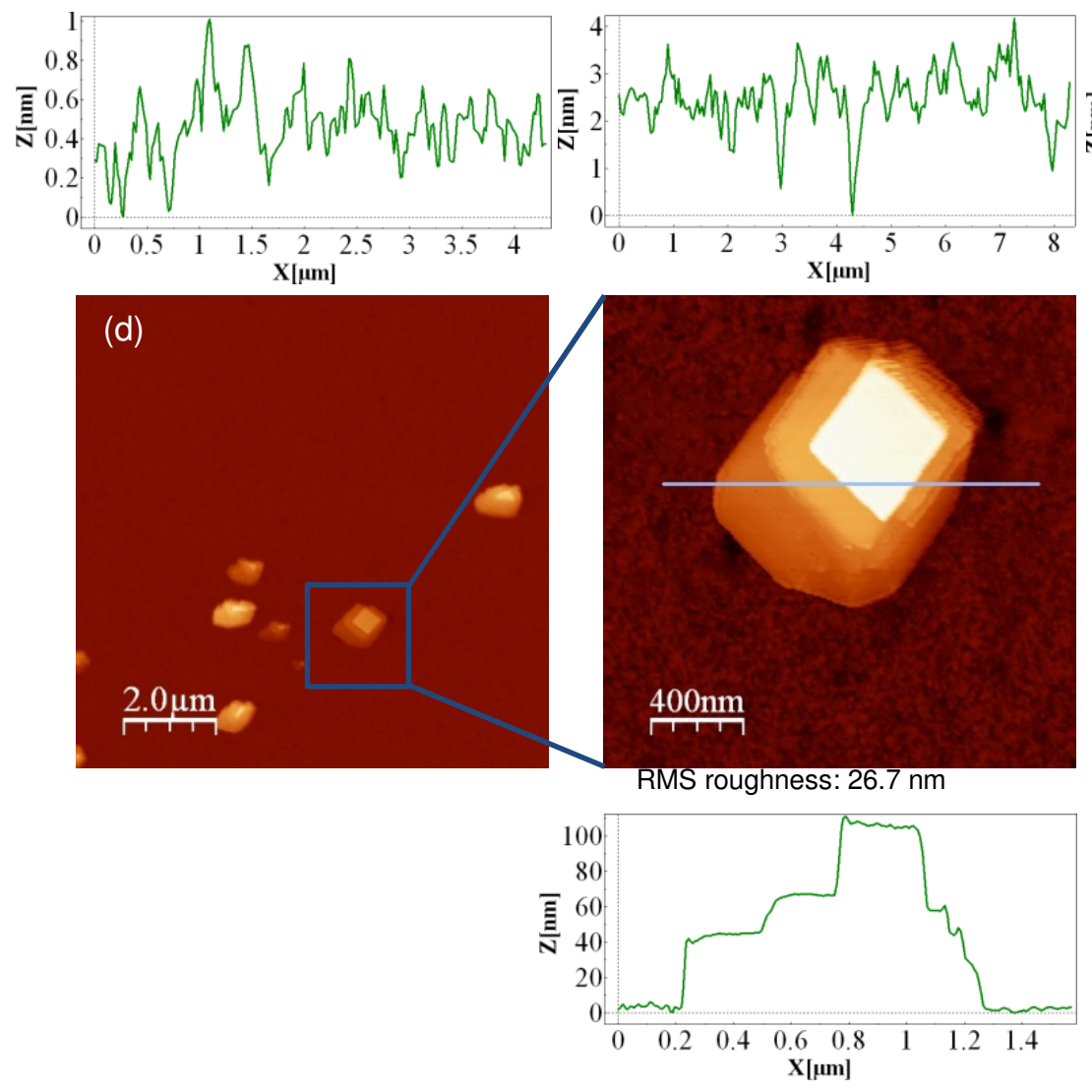

RMS roughness: $26.7 \mathrm{~nm}$
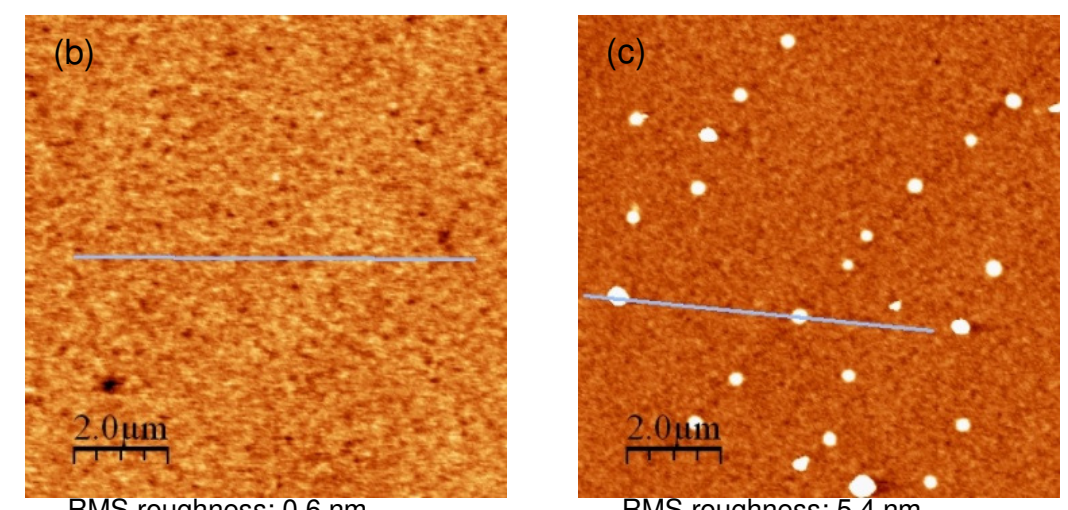

RMS roughness: $5.4 \mathrm{~nm}$
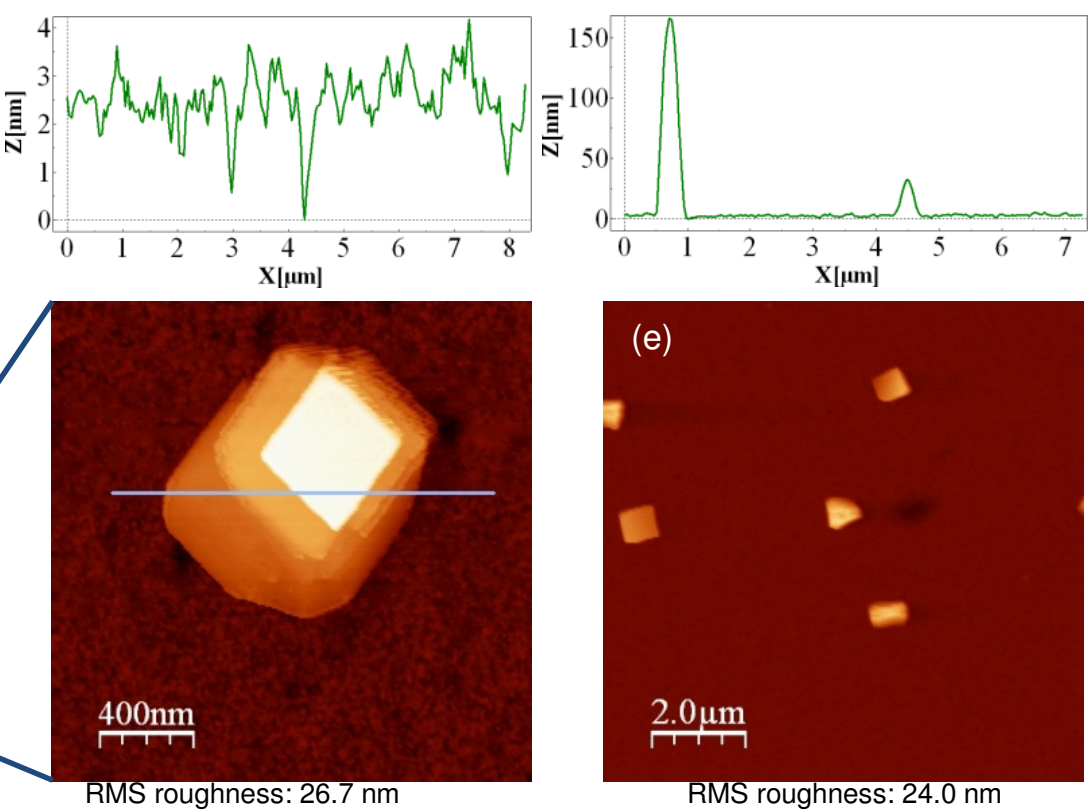

RMS roughness: $24.0 \mathrm{~nm}$

Figure 9 Crystal development with time in 15PD-90 films $(78 \pm 8 \mathrm{~nm})$ on annealing at $130{ }^{\circ} \mathrm{C}$ :

(a) as-spin-cast, (b) $4 \mathrm{hr}$, (c) $8 \mathrm{hr}$, (d) $16 \mathrm{hr}$, (e) $65 \mathrm{hr}$. Crystalline aggregations form first and then develop into multilayer crystals.

In contrast to 2M13PD-extended TPU thin films, no seaweed flat-on crystals were observed in 15PD-extended TPU thin films of similar thickness. The morphological development of as-spin-cast 15PD-90 films around $78 \mathrm{~nm}$ thick annealed at $130{ }^{\circ} \mathrm{C}$ for various times, Figure 9 , 
exemplified in the development of large crystals. These AFM results allow us to have a better understanding of the growth of the crystal blocks in high HS-content polyurethane thin films. The annealing temperature is roughly $10 \mathrm{~K}$ over the bulk $T_{\mathrm{c}}$ of $15 \mathrm{PD}-90$. At the early stage of annealing, e.g. after $4 \mathrm{hr}$ annealing, ordering of HS occurred resulting in the surface pits with depth of one or two nanometres (Figure 9b). Aggregations of heights between 20 and $160 \mathrm{~nm}$ were then observed after an $8 \mathrm{hr}$ anneal (Figure 9c), and after $16 \mathrm{hr}$ annealing, only multilayer crystals with evident steps were found with similar heights to the earlier aggregations (Figure 9d), suggesting they had developed from the preformed aggregations. This extraordinary aggregation-crystallization process allows the polymer chains to arrange themselves into big lamellar crystal blocks with total thickness reaching hundreds of nanometres proud of the surface, because such ordering on this scale cannot occur within the thickness of these films. With more annealing time, the stepped crystals developed into crystal blocks and after $65 \mathrm{hr}$ annealing developed no further (Figure 9e).

\section{CONCLUSIONS}

In 2M13PD-extended TPU thin films, although no phase separation was observed in as-spin-cast thin films (in contrast to melt-quenched bulk samples), HS ordering and the formation of phase-separated mesophase domains were directly observed on annealing, which agrees well with the bulk results. In addition, the formation of large crystals blocks was observed at higher annealing temperatures, and large seaweed flat-on crystals were additionally formed in some cases. The large crystals are believed to form exclusively in thin films with thickness below about $100 \mathrm{~nm}$, as no such phenomenon observed in thicker films, and there is no evidence for their formation in previous, bulk studies. A lower HS content allows a lower phase separation and crystallization temperature, yet TPU films with various HS contents show a similar morphological evolution on annealing. 
15PD-extended HS showed a higher compatibility with SS, and so no phase separation was observed in 15PD-extended thin films with thickness around $75 \mathrm{~nm}$, through this apparent miscibility is thought to be specific to the thin-film case. Similar large crystal blocks have also been found in these thin films.

Thus, there are many similarities in the behaviour observed in thin films, compared with bulk, and the morphologies can be observed directly with AFM. However, there are key differences, such as the possibility to create a single-phase mixed state on casting, more hindered phase separation, and the formation of very large blocky crystals.

\section{ACKNOWLEDGEMENT}

LJ, JW \& HEA acknowledge assistance from Sverre Myhra with AFM training and advice, and Prof Andrew Watt with TEM assistance. CN and AS acknowledge Huntsman Polyurethane for funding.

Supporting information available: DSC traces, XPS of 2M13PD-80, electron diffraction of region between crystallites, AFM of $140^{\circ} \mathrm{C}$ annealed 2M13PD-100, AFM of morphology trends with film thickness. This material is available free of charge via the Internet at http://pubs.acs.org.

\section{REFEREMCES}

(1) Koberstein, J. T.; Stein, R. S. Journal of Polymer Science: Polymer Physics Edition 1983, 21, 1439-1472.

(2) Buckley, C. P.; Prisacariu, C.; Martin, C. Polymer 2010, 51, 3213-3224.

(3) Li, F.; Hou, J.; Zhu, W.; Zhang, X.; Xu, M.; Luo, X.; Ma, D.; Kim, B. K. Journal of Applied Polymer Science 1996, 62, 631-638.

(4) Seefried Jr., C. G.; Koleske, J. V.; Critchfield, F. E. Journal of Applied Polymer Science 1975, 19, 2493-2502. 
(5) Seefried Jr., C. G.; Koleske, J. V.; Critchfield, F. E. Journal of Applied Polymer Science 1975, 19, 2503-2513.

(6) Korley, L. T. J.; Pate, B. D.; Thomas, E. L.; Hammond, P. T. Polymer 2006, 47, 30733082.

(7) Sonnenschein, M. F.; Lysenko, Z.; Brune, D. A.; Wendt, B. L.; Schrock, A. K. Polymer 2005, 46, 10158-10166.

(8) Hernandez, R.; Weksler, J.; Padsalgikar, A.; Choi, T.; Angelo, E.; Lin, J. S.; Xu, L. C.; Siedlecki, C. A.; Runt, J. Macromolecules 2008, 41, 9767-9776.

(9) Seymour, R. W.; Cooper, S. L. Macromolecules 1973, 6, 48-53.

(10) Van Bogart, J. W. C.; Bluemke, D. A.; Cooper, S. L. Polymer 1981, 22, 1428-1438.

(11) Koberstein, J. T.; Galambos, A. F. Macromolecules 1992, 25, 5618-5624.

(12) Koberstein, J. T.; Galambos, A. F.; Leung, L. M. Macromolecules 1992, 25, 6195-6204.

(13) Koberstein, J. T.; Leung, L. M. Macromolecules 1992, 25, 6205-6213.

(14) Leung, L. M.; Koberstein, J. T. Macromolecules 1986, 19, 706-713.

(15) Chen, T. K.; Shieh, T. S.; Chui, J. Y. Macromolecules 1998, 31, 1312-120.

(16) Saiani, A.; Novak, A.; Rodier, L.; Eeckhaut, G.; Leenslag, J. W.; Higgins, J. S. Macromolecules 2007, 40, 7252-7262.

(17) Saiani, A.; Daunch, W. A.; Verbeke, H.; Leenslag, J. W.; Higgins, J. S. Macromolecules 2001, 34, 9059-9068.

(18) Saiani, A.; Rochas, C.; Eeckhaut, G.; Daunch, W. A.; Leenslag, J. W.; Higgins, J. S. Macromolecules 2004, 37, 1411-1421.

(19) Yanagihara, Y.; Osaka, N.; Murayama, S.; Saito, H. Polymer 2013, 54, 2183-2189.

(20) Shinotsuka, K.; Bliznyuk, V. N.; Assender, H. E. Polymer 2012, 53, 5554-5559.

(21) Meuse, C. W.; Yang, X.; Yang, D.; Hsu, S. L. Macromolecules 1992, 25, 925-932.

(22) Tao, H. J.; Meuse, C. W.; Yang, X.; MacKnight, W. J.; Hsu, S. L. Macromolecules 1994, 27, 7146-7151.

(23) Kojio, K.; Uchiba, Y.; Mitsui, Y.; Furukawa, M.; Sasaki, S.; Matsunaga, H.; Okuda, H. Macromolecules 2007, 40, 2625-2628.

(24) Horcas, I.; Fernandez, R.; Gomez-Rodriguez, J. M.; Colchero, J.; Gomez-Herrero, J.; Baro, A. M. Rev. Sci. Instrum. 2007, 78, 013705.

(25) Novillo, F. A.; Fujita, M.; Tsuji, M.; Kohjiya, S. Sen-I Gakkaishi 1998, 54, 544-549.

(26) Rees, D. V.; Bassett, D. C. Journal of Materials Science 1971, 6, 1021-1035. 